\title{
The control of blood pressure might be important in delaying progression of arterial aging in patients with type 2 diabetes mellitus
}

\author{
GeeHee Kim' \\ Ji-Hoon Kim' \\ Keon-Woong Moon' \\ Ki-Dong Yoo' \\ Seung-Hyun $\mathrm{Ko}^{2}$ \\ Yu-Bae Ahn² \\ Chul-Min Kim' \\ 'Division of Cardiology, ${ }^{2}$ Division \\ of Endocrinology and Metabolism, \\ Department of Internal Medicine, \\ St Vincent's Hospital, Catholic \\ University of Korea, Suwon, \\ Republic of Korea
}

This article was published in the following Dove Press journal:

Clinical Interventions in Aging

II August 2014

Number of times this article has been viewed
Objective: Arterial stiffness, as assessed by the brachial-ankle pulse wave velocity (baPWV), is associated with arterial aging and has been consistently linked to cardiovascular disease. The factors involved in reducing the progression of arterial stiffness in patients with type 2 diabetes mellitus (DM) have not yet been fully established.

Methods: Of 478 patients who underwent two baPWV measurements (at baseline and 1 year later) at the Department of Internal Medicine, St Vincent's Hospital, from November 2009 to June 2011, 341 subjects were enrolled in this study (male to female ratio $=150: 191$; mean age, $62.1 \pm 7.7$ years). The 341 subjects were over the age of 50 with type $2 \mathrm{DM}$, were diagnosed without peripheral artery disease, and 170 if the subjects $(50 \%)$ had hypertension.

Results: baPWV at baseline increased in a linear manner along with age $(\beta=22.8, t=10.855$; $\left.P<0.0001, R^{2}=0.258\right)$. After 1 year follow-up, the change in baPWV ( $\triangle$ baPWV) was variable (median $32.7 \mathrm{~cm} / \mathrm{s}$ [approximate range, -557 to $\sim 745$ ]). In multiple linear regression, the change in systolic blood pressure $\left(\beta=7.142,95 \%\right.$ confidence interval $\left.=4.557-9.727 ; P<0.0001, R^{2}=0.305\right)$ was associated with $\triangle \mathrm{baPWV}$ during follow-up. The change in glycated hemoglobin $\left(\mathrm{HbA}_{1 \mathrm{c}}\right)$ and a glycemic control of keeping $\mathrm{HbA}_{1 \mathrm{c}}$ levels below $7.0 \%$ were not associated with $\triangle \mathrm{baPWV}$.

Conclusion: We found that the variation of blood pressure was associated with the progression of vascular aging of the large- to middle-sized arteries in patients with type $2 \mathrm{DM}$. Therefore, control of blood pressure might be important in reducing arterial aging or PWV in patients with type $2 \mathrm{DM}$.

Keywords: arterial aging, blood pressure, diabetes mellitus

\section{Introduction}

Pulse wave velocity (PWV), an indicator of arterial stiffness, is an independent predictor of cardiovascular morbidity and mortality. ${ }^{1}$ The brachial-ankle PWV (baPWV) has been closely correlated with the carotid-femoral PWV, a noninvasive gold-standard marker for the assessment of aortic stiffness. ${ }^{2}$ Measurement of baPWV is widely used in the general population because it has good reproducibility and does not require special skills from the technician. ${ }^{3}$

PWV has a strong dependence on age and blood pressure (BP). ${ }^{4}$ In a previous study, the annual rate of change in baPWV in healthy subjects was higher in the group with persistence of prehypertension than in the group with blood pressure in the normal range. Also, persistence of prehypertension accelerated structural stiffening of the large- to medium-sized arteries, and this type of aging may exert a synergistic effect on the acceleration of arterial stiffening. ${ }^{2}$

Aging is associated with structural and functional changes in the vessel wall and elevated arterial stiffness. ${ }^{5,6}$ The annual increase in aortic PWV before the age of
Correspondence: Ji-Hoon Kim Division of Cardiology, Department of Internal Medicine, St Vincent's Hospital, 93-6, Ji-dong, Paldal-ku, Suwon, Gyeonggi-do, 442-723, Republic of Korea Tel +82312497139

Fax +82 3I 2477139

Email anthleemd@naver.com 
50 years is approximately $100 \mathrm{~mm} / \mathrm{s}$ and rises to more than $150 \mathrm{~mm} / \mathrm{s}$ after the age 60 years. ${ }^{7,8}$ Aging progression may be more pronounced in middle-aged and elderly subjects in healthy populations. ${ }^{2}$

Several studies have reported that a higher baPWV is associated with more advanced latent and clinically atherosclerotic lesions of the arterial wall in hypertension (HBP). ${ }^{9}$ Also, type 2 diabetes mellitus (DM) is a well-known cardiovascular risk factor often associated with and characterized by increased arterial stiffness. ${ }^{10}$ However, in patients with type $2 \mathrm{DM}$, factors influencing progression of baPWV have not yet been fully established. In this study, we report on factors that may reduce the progression of arterial stiffness in patients with type $2 \mathrm{DM}$.

\section{Methods}

\section{Study population}

We retrospectively enrolled 478 patients who underwent two baPWV measurements (ie, at baseline and again 1 year later) at the Medical Department of St Vincent's Hospital, Suwon, South Korea from November 2009 to June 2011. We excluded subjects with peripheral artery disease as diagnosed by an ankle-brachial index (ABI), subjects under the age of 50 years, and subjects without type 2 DM. Subjects $(\mathrm{N}=341)$ with type $2 \mathrm{DM}$ over the age of 50 years (male to female ratio $=150: 191$; mean age, 62.1 \pm 7.7 years) were enrolled in this study. Controlled DM was defined as achieving and keeping glycated hemoglobin $\left(\mathrm{HbA}_{1 \mathrm{c}}\right)$ levels at $7.0 \%$. There was no industry involvement in the design, conduct, or analysis of the study. The Ethics Committee of St Vincent's Hospital approved the use of clinical data for this study, and all patients provided written informed consent.

\section{PWV measurements}

Bilateral brachial and ankle BPs and arterial pulse waves were simultaneously measured using an automatic waveform analyzer (VP-1000; Omron Healthcare, Kyoto, Japan).

Individuals were examined in the supine position after at least 5 minutes bed rest. Pneumatic cuffs were wrapped around both upper arms and ankles, and connected to a plethysmographic sensor to determine the volume pulse waveform. Bilateral brachial and posterior tibial artery pressure waveforms were stored for a 10 second sample time with automatic gain analysis and quality adjustment. baPWV was recorded and calculated using the formula

$$
(\mathrm{L} 1-\mathrm{L} 2) / \mathrm{T}
$$

in which L1 and L2 were defined as the distance from the heart to the ankle, and the distance from the heart to the brachium, respectively, and $\mathrm{T}$ was defined as the transit time between the brachial and posterior tibial artery waveforms. The average of baPWV measurements taken from the left and right sides were used for the analysis. The change in baPWV during the study period ( $\triangle \mathrm{baPWV}$ ) was calculated as follows:

value at the second examination - value at the baseline examination.

The ABI was defined as the bilateral ratio of the systolic BP of the posterior tibial artery to that of the brachial artery.

\section{Clinical and biochemical assessment}

Blood specimens were collected after a 12- to 14-hour fast ( $8 \mathrm{pm}$ to $9.30 \mathrm{am}$ ) to reduce the influence of circadian variation. Total cholesterol and triglyceride concentrations were measured using standard enzyme methods. Highdensity lipoprotein cholesterol was measured after precipitation of very-low-density lipoproteins and low-density lipoprotein with phosphotungstic acid, and low-density lipoprotein was calculated using the Friedewald formula. Fasting glucose levels were enzymatically determined by the hexokinase method. ${ }^{11}$ A blood sample from every patient was drawn and centrifuged within 30 minutes; serum samples were stored at $-80^{\circ} \mathrm{C}$, and high sensitivity $\mathrm{C}$-reactive protein was determined using an immunoturbidity assay system (Liatest; Stago, Asnières-sur-Seine, France), with an interassay variability coefficient of variation of $6.25 \% .^{12}$

\section{Blood pressure measurement}

Blood pressure was measured with a mercury sphygmomanometer (YAMASU, Saitama, Japan), (first and fifth phases of the Koroktoff sounds taken as systolic BP and diastolic $\mathrm{BP}$, respectively) after subjects had rested for 5 minutes in the sitting position. An average of three measurements was used in the analysis. Systemic hypertension was defined as systolic pressure $\geq 140 \mathrm{mmHg}$ and/or diastolic pressure $\geq 90 \mathrm{mmHg}$, based on more than three measurements or current use of antihypertensive drugs. BP measurements were performed blinded to baPWV measurements.

\section{Statistical analysis}

Statistical analysis was performed using R (version 2.15.1; Institute for Statistics and Mathematics of Wirtschaft 
University, Vienna, Austria). Continuous values are expressed as the means \pm standard deviation (SD). The means were compared by the Student's $t$-test for independent samples with the assumption of equal variance, and also the paired $t$-test for dependent samples. Analysis of categorical data was carried out with the $\chi^{2}$ test or Fischer's exact test, where appropriate. The limit of statistical significance was set at $P<0.05$. Variables yielding $P$-values $<0.05$ by univariate analysis and variables considered clinically relevant, were entered into the multivariate analysis to estimate the independent association of each covariate with the dependent variable. Multivariate analysis consisted of linear regression analysis for independent variables related to the change in $\triangle \mathrm{baPWV}$.

\section{Results}

Baseline characteristics of the 341 patients with type $2 \mathrm{DM}$ over the age of 50 at the first visit are shown in Table 1. All patients without peripheral artery disease were diagnosed by ABI. At the first visit, the mean age of study subjects was 62.1 \pm 7.7 years, and $150(44 \%)$ were men. baPWV at baseline increased in a linear manner with age $(\beta=22.8, t=10.855$; $P<0.001, r=0.508$ ) (Figure 1). All patients underwent baPWV measurements twice (ie, at baseline and 1 year later; mean, $351 \pm 60$ days). After 1-year follow-up, $\triangle \mathrm{baPWV}$ was variable (median $32.7 \mathrm{~m} / \mathrm{s}$ [range, -557 to $\sim 745]$ ). Table 2 shows the correlation between $\triangle \mathrm{baPWV}$ and multiple risk factors. $\triangle$ baPWV was associated with systolic BP, diastolic BP,

Table I Clinical characteristics of subjects (patients) at baseline

\begin{tabular}{ll}
\hline Variable & All patients N=34I \\
\hline Age, years & $62.1 \pm 7.7$ \\
Males, $\mathrm{n}(\%)$ & $\mathrm{I} 50(44 \%)$ \\
Smokers, $\mathrm{n}(\%)$ & $69(20 \%)$ \\
History of cerebrovascular disease, $\mathrm{n}(\%)$ & $19(5.6 \%)$ \\
Diabetes mellitus duration, years & $12.3 \pm 7.4$ \\
Hypertension, $\mathrm{n}$ (\%) & $\mathrm{I} 70(50 \%)$ \\
Hypertension duration, years & $4.6 \pm 6.5$ \\
Body mass index, $\mathrm{kg} / \mathrm{m}^{2}$ & $25.0 \pm 3.3$ \\
Fasting plasma glucose, $\mathrm{mg} / \mathrm{dL}$ & $147 \pm 60$ \\
Glycated hemoglobin, \% & $8.0 \pm \mathrm{I} .5$ \\
Total cholesterol, $\mathrm{mg} / \mathrm{dL}$ & $179 \pm 40$ \\
Triglyceride, $\mathrm{mg} / \mathrm{dL}$ & $126 \pm 73$ \\
High-density lipoprotein, $\mathrm{mg} / \mathrm{dL}$ & $44 \pm \mathrm{II}$ \\
Low-density lipoprotein, $\mathrm{mg} / \mathrm{dL}$ & $10 \mathrm{I} \pm 33$ \\
Creatinine, $\mathrm{mg} / \mathrm{dL}$ & $0.89 \pm 0.3$ \\
hsCRP, $\mathrm{mg} / \mathrm{dL}$ & $0.09($ range $0.0 \mathrm{I}-38.4)$ \\
Systolic blood pressure, $\mathrm{mmHg}$ & $\mathrm{I} \mathrm{II} \pm \mathrm{I} 5$ \\
Diastolic blood pressure, $\mathrm{mmHg}$ & $78 \pm 9$ \\
Pulse pressure, $\mathrm{mmHg}$ & $53 \pm \mathrm{II}$ \\
\hline
\end{tabular}

Abbreviations: $\mathrm{N}$, number of subjects; hs CRP, high-sensitivity C-reactive protein.

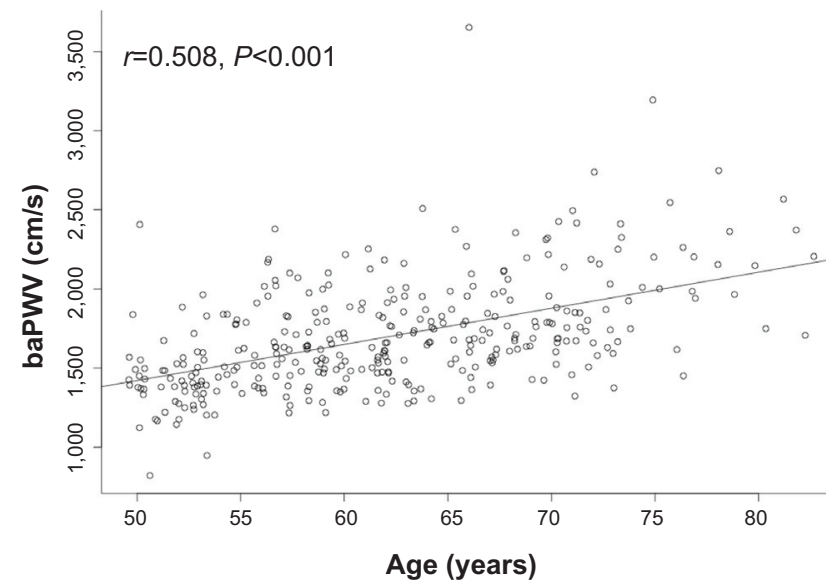

Figure I Plot of pulse wave velocity (PWV) in relation to age of patients with diabetes mellitus.

Abbreviation: baPWV, brachial-ankle pulse wave velocity.

and pulse pressure at the second visit. Also, $\triangle$ baPWV was related to the change in systolic $\mathrm{BP}(\triangle \mathrm{SBP}$; median, $0 \mathrm{mmHg}$ [range, -68 to $\sim 46 \mathrm{mmHg}$ ]) (Figure 2); the change in diastolic $\mathrm{BP}$ (median, $0 \mathrm{mmHg}$ [range, -33 to $\sim 46 \mathrm{mmHg}$ ); the change in pulse pressure (median, $0 \mathrm{mmHg}$ [range, -35 to $\sim 31 \mathrm{mmHg}$ ); the change in total cholesterol (median, $-10 \mathrm{mg} / \mathrm{dL}$ [range, -148 to $\sim 150 \mathrm{mmHg}$ ]); and the change in high-density lipoprotein (median, $0 \mathrm{mg} / \mathrm{dL}$ [range, -49 to $\sim 32 \mathrm{mmHg}$ ]). In multivariate analysis, $\triangle \mathrm{SBP}$ was associated with the progression of baPWV during follow-up (Table 3).

In subgroup analysis, 65 patients (19.1\%) had controlled DM. However, the change in $\mathrm{HbA}_{\mathrm{lc}}\left(\Delta \mathrm{HbA}_{1 \mathrm{c}}\right.$; median, $0.2 \%$ [range, $-4.9 \%$ to $\sim 3.25 \%$ ]; $P=0.276$ ) was not associated with $\triangle$ baPWV. Also, patients with controlled DM were not associated with $\triangle \mathrm{baPWV}(P=0.276)$. There were several diabetic complications, such as retinopathy $(\mathrm{n}=200,58.7 \%)$; autonomic neuropathy $(\mathrm{n}=37,10.9 \%)$; microalbuminuria $(\mathrm{n}=161,47.2 \%)$; and nephropathy $(\mathrm{n}=28,8.2 \%)$. Furthermore, patients with autonomic neuropathy were not associated with $\triangle \mathrm{baPWV}(P=0.057)$.

Table 2 Pearson correlation between $\triangle$ baPWV and multiple risk factors (variables)

\begin{tabular}{lll}
\hline Variable & Coefficient & P-value \\
\hline Systolic BP at second visit & 0.273 & $<0.000 \mathrm{I}$ \\
Diastolic BP at second visit & 0.273 & $<0.000 \mathrm{I}$ \\
Pulse pressure at second visit & 0.178 & $0.00 \mathrm{I}$ \\
Change in systolic BP & 0.534 & $<0.000 \mathrm{I}$ \\
Change in diastolic BP & 0.454 & $<0.000 \mathrm{I}$ \\
Change in pulse pressure & 0.387 & $<0.000 \mathrm{I}$ \\
Change in total cholesterol & 0.118 & $0.03 \mathrm{I}$ \\
Change in high-density lipoprotein & 0.160 & 0.003 \\
\hline
\end{tabular}

Abbreviations: $\triangle$ baPWV, change in brachial-ankle pulse wave velocity; BP, blood pressure. 


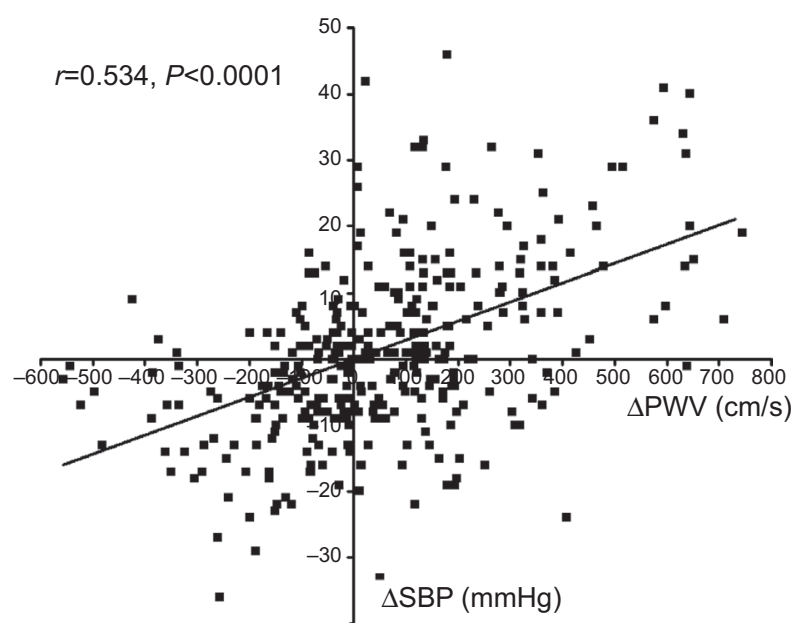

Figure 2 Plot showing the correlation of changes in pulse wave velocity $(\triangle \mathrm{PWV})$ with changes in systolic blood pressure $(\triangle \mathrm{SBP})$.

\section{Discussion}

The present study is a longitudinal study to evaluate the determinants of the progression of arterial stiffness over a period of 1 year. This study shows that the progression of baPWV in patients with type $2 \mathrm{DM}$ over the age of 50 was correlated with a change in systolic BP at follow-up. $\triangle \mathrm{SBP}$ was identified as being responsible for accelerated progression of baPWV in patients with type $2 \mathrm{DM} . \Delta \mathrm{HbA}_{1 \mathrm{c}}$, and a glycemic control of keeping $\mathrm{HbA}_{1 \mathrm{c}}$ levels below $7.0 \%$, were not associated with $\triangle \mathrm{baPWV}$.

Arterial stiffness has been shown to be an independent predictor of cardiovascular mortality, and greatly increases with age. ${ }^{13}$ Arterial stiffness is increased when elastic properties of the arterial wall are reduced. ${ }^{14}$ Aging is a process that causes structural and functional modifications in the vasculature, resulting in decreased arterial compliance and ability of arteries to withstand strain. ${ }^{7}$ Several cross-sectional studies have shown that in addition to age, several other environmental and genetic factors can influence arterial stiffness. ${ }^{15-17}$ The striking features of arterial stiffening are an increased density of collagen fibers, decreased density

Table 3 Comparison of $\triangle$ baPWV by multiple linear regression according to risk factors (variables)

\begin{tabular}{llll}
\hline Variable & $\boldsymbol{\beta}$ & $\mathbf{C l}$ & $\boldsymbol{P}$-value \\
\hline Systolic BP at second visit & 0.666 & $0.563-\mathrm{I} .230$ & 0.490 \\
Diastolic BP at second visit & 3.156 & $0.340-6.652$ & 0.077 \\
Change in total cholesterol & 0.174 & $0.295-0.643$ & 0.469 \\
Change in high-density lipoprotein & 2.386 & $0.021-4.752$ & 0.048 \\
Change in systolic BP & 7.142 & $4.557-9.727$ & $<0.000 \mathrm{I}$ \\
Change in diastolic BP & $2.40 \mathrm{I}$ & $0.439-6.238$ & 0.220 \\
\hline
\end{tabular}

Abbreviations: $\triangle$ baPWV, change in brachial-ankle pulse wave velocity; BP, blood pressure; $\mathrm{Cl}$, confidence interval. of elastic fibers, the accumulation of advanced glycation end-products on collagen and elastin fibers, and endothelial dysfunction. $^{18}$

In a previous longitudinal study, uncontrolled BP and increased heart rate (HR) could have accelerated agerelated progression of arterial stiffness using aortic PWV as a measure over a 6-year period in treated hypertensive subjects. ${ }^{19}$ In another study, persistence of prehypertension, not HR, was associated with progressive arterial stiffness using baPWV as a measure. ${ }^{2}$ However, in treated type $2 \mathrm{DM}$ patients, the role of risk factors on the progression of arterial stiffness using baPWV as a measure has not yet been evaluated. This study showed that changes in systolic BP could have accelerated the progression of arterial damage, by using baPWV as a measure in treated type $2 \mathrm{DM}$ patients.

Some limitations to our study deserve mention. First, baPWV is not considered the gold standard for assessing arterial stiffness. ${ }^{20}$ However, the validity and reproducibility of baPWV measurements are very high, and this method seems to be an acceptable marker reflecting vascular damage. baPWV measured by this simple, noninvasive method is suitable for screening vascular damage. Second, a limitation of the present study is that the effect of different BP lowering therapies was not considered. However, most patients (over 90\%) were taking more than one BP-lowering drug, including angiotensin-converting enzyme (ACE) inhibitors, or angiotensin II receptor blockers (ARBs).

In conclusion, the present longitudinal study shows that $\triangle \mathrm{SBP}$ was associated with the progression of vascular aging of the large- to middle-sized arteries in patients with type 2 DM. Therefore, BP control might be important factor in reducing arterial aging or PWV in patients with type 2 DM.

\section{Disclosure}

The authors report no conflicts of interest in this work.

\section{References}

1. Vlachopoulos C, Aznaouridis K, Stefanadis C. Prediction of cardiovascular events and all-cause mortality with arterial stiffness: a systematic review and meta-analysis. J Am Coll Cardiol. 2010;55(13): 1318-1327.

2. Tomiyama H, Hashimoto H, Matsumoto C, et al. Effects of aging and persistence prehypertension on arterial stiffening. Atherosclerosis. 2011;217(1):130-134.

3. Yamashina A, Tomiyama H, Takeda K, et al. Validity, reproducibility, and clinical significance of noninvasive brachial-ankle pulse wave velocity measurement. Hypertens Res. 2002;25(3):359-364.

4. Reference Values for Arterial Stiffness' Collaboration. Determinants of pulse wave velocity in healthy people and in the presence of cardiovascular risk factors: 'establishing normal and reference values'. Eur Heart J. 2010;31(19):2338-2350. 
5. Avolio AP, Chen SG, Wang RP, Zhang CL, Li MF, O'Rourke MF. Effects of aging on changing arterial compliance and left ventricular load in a northern Chinese urban community. Circulation. 1983;68(1):50-58.

6. Mattace-Raso FU, van der Cammen TJ, Hofman A, et al. Arterial stiffness and risk of coronary heart disease and stroke: the Rotterdam Study. Circulation. 2006;113(5):657-663.

7. Benetos A, Salvi P, Lacolley P. Blood pressure regulation during the aging process: the end of the 'hypertension era'? J Hypertens. 2011;29(4):646-652.

8. Benetos A, Buatois S, Salvi P, et al. Blood pressure and pulse wave velocity values in the institutionalized elderly aged 80 and over: baseline of the PARTAGE study. J Hypertens. 2010;28(1):41-50.

9. Munakata M, Nunokawa T, Tayama J, Yoshinaga K, Toyota T. Brachial-ankle pulse wave velocity as a novel measure of arterial stiffness: present evidences and perspectives. Curr Hypertens Rev. 2005;1(3):223-234.

10. Aso K, Miyata M, Kubo T, et al. Brachial-ankle pulse wave velocity is useful for evaluation of complications in type two diabetic patients. Hypertens Res. 2003;26(10):807-813.

11. Iannuzzi A, De Michele M, Bond MG, et al. Carotid artery remodeling in middle-aged women with the metabolic syndrome (from the "Progetto ATENA" study). Am J Cardiol. 2005;96(8):1162-1165.

12. Hamano M, Saito M, Eto M, et al. Serum amyloid A, C-reactive protein and remnant-like lipoprotein particle cholesterol in type 2 diabetic patients with coronary heart disease. Ann Clin Biochem. 2004;41(Pt 2):125-129.
13. Cruickshank K, Riste L, Anderson SG, Wright JS, Dunn G, Gosling RG Aortic pulse-wave velocity and its relationship to mortality in diabetes and glucose intolerance: an integrated index of vascular function? Circulation. 2002;106(16):2085-2090.

14. Greenwald SE, Carter AC, Berry CL. Effect of age on the reflection coefficient of the aortoiliac junction in humans. Circulation. 1990;82(1):114-123.

15. Avolio AP, Deng FQ, Li WQ, et al. Effects of aging on arterial distensibility in populations with high and low prevalence of hypertension: comparison between urban and rural communities in China. Circulation . 1985;71(2):202-210.

16. Avolio A. Genetic and environmental factors in the function and structure of the arterial wall. Hypertension. 1995;26(1):34-37.

17. Lajemi M, Labat C, Gautier S, et al. Angiotensin II type 1 receptor$153 \mathrm{~A} / \mathrm{G}$ and $1166 \mathrm{~A} / \mathrm{C}$ gene polymorphisms and increase in aortic stiffness with age in hypertensive subjects. J Hypertens. 2001;19(3):407-413.

18. Dao HH, Essalihi R, Bouvet C, Moreau P. Evolution and modulation of age-related medial elastocalcinosis: impact on large artery stiffness and isolated systolic hypertension. Cardiovasc Res. 2005;66(2):307-317.

19. Benetos A, Adamopoulos C, Bureau JM, et al. Determinants of accelerated progression of arterial stiffness in normotensive subjects and in treated hypertensive subjects over a 6-year period. Circulation. 2002;105(10):1202-1207.

20. Laurent S, Cockcroft J, Van Bortel L, et al. Expert consensus document on arterial stiffness: methodological issues and clinical applications. Eur Heart J. 2006;27(21):2588-2605.
Clinical Interventions in Aging

\section{Publish your work in this journal}

Clinical Interventions in Aging is an international, peer-reviewed journal focusing on evidence-based reports on the value or lack thereof of treatments intended to prevent or delay the onset of maladaptive correlates of aging in human beings. This journal is indexed on PubMed Central, MedLine,

\section{Dovepress}

CAS, Scopus and the Elsevier Bibliographic databases. The manuscript management system is completely online and includes a very quick and fair peer-review system, which is all easy to use. Visit http://www.dovepress. com/testimonials.php to read real quotes from published authors. 